\title{
Climate Change and Ecological Engineering Jointly Induced Vegetation Greening in Global Karst Regions From 2001 to 2020
}

Jing Huang ( $\sim$ jingjing520@email.swu.edu.cn )

Southwest University https://orcid.org/0000-0003-1378-6906

Zhongxi Ge

Southwest University, School of Geographical Sciences

Yuqing Huang

Nanning Normal University

\section{Xuguang Tang}

Southwest University, School of Geographical Sciences

\section{Zhan Shi}

Southwest University, School of Geographical Sciences

\section{Peiyu Lai}

Southwest University, School of Geographical Sciences

\section{Zengjing Song}

Southwest University, School of Geographical Sciences

\section{Binfei Hao}

Guangdong Ocean University

Hong Yang ( $\sim$ h.yang4@reading.ac.uk )

Southwest University

\section{Mingguo Ma}

Southwest University, School of Geographical Sciences

\section{Research Article}

Keywords: Vegetation greenness trends, SINDVI, Climate factors, Human activities, Global karst regions

Posted Date: June 1st, 2021

DOI: https://doi.org/10.21203/rs.3.rs-192599/v1

License: (c) (1) This work is licensed under a Creative Commons Attribution 4.0 International License.

Read Full License 


\section{Climate Change and Ecological Engineering Jointly Induced}

3 Vegetation Greening in Global Karst Regions From 2001 to 2020

4 Jing Huang ${ }^{1,2,3}$, Zhongxi Ge ${ }^{1,2,3}$, Yuqing Huang ${ }^{5}$, Xuguang Tang ${ }^{1,2,3}$, Zhan Shi ${ }^{1}$, Peiyu Lai ${ }^{1,2,3}$,

5 Zengjing Song ${ }^{1,2,3}$, Binfei Hao ${ }^{6}$, Hong Yang ${ }^{2,4}$, Mingguo $\mathrm{Ma}^{1,2,3}$

61 Southwest University, School of Geographical Sciences, Chongqing Jinfo Mountain Field Scientific Ob-

7 servation and Research Station for Karst Ecosystem, Ministry of Education, Chongqing 400715, China;

82 Chongqing Engineering Research Center for Remote Sensing Big Data Application, School of Geo-

9 graphical Sciences, Southwest University, Chongqing 400715, China;

103 Chongqing Key Laboratory of Karst Environment, School of Geographical Sciences, Southwest Univer-

11 sity, Chongqing 400715, China;

124 Department of Geography and Environmental Science, University of Reading, Whiteknights Reading, 13 RG6 6AB, UK;

145 Key Laboratory of Beibu Gulf Environment Change and Resource Use, Ministry of Education ,Nanning 15 Normal University, Nanning 530000, China;

166 College of Electronics and Information Engineering, Guangdong Ocean University, Zhanjiang 524088, 17 China.

18 Corresponding author: Mingguo Ma; Hong Yang

19 Address: Tiansheng Road No.2, Beibei District, Chongqing 400715, China;

20 Whiteknights, RG6 6AB, Reading, Berkshire, United Kingdom

21 Tel: +86-23-6825-4917; 0044(0)1183787750

22 Fax: +86-23-6825-4917

23 Email: mmg@swu.edu.cn; $\underline{\text { h.yang4@ reading.ac.uk }}$ 
Backgrounds Vegetation dynamic plays a dominant role in the global carbon cycle and climate, especially in vulnerable karst ecosystem. Many studies have examined past several decades changes in vegetation greenness and the associated with climate drivers. Yet, few studies have analyzed the vegetation change in global karst regions particularly in the last decades when climate change and anthropogenic disturbance widely occurred. Methods In this study, we investigated the spatio-temporal variations of vegetation dynamic using the Seasonally Integrated Normalized Difference Vegetation Index (SINDVI) and examined their relationship to climate changes by correlation analysis, the ordinary least squares method investigate the variation trends and the MannKendal test to detect the turning point from 2001 to 2020.

Results As expected, there have greening trend in global karst SINDVI from 2001 to 2020, with significant increasing trend in China (range $=0.836, \mathrm{P}<0.05$ ), Europe (range $=0.456, \mathrm{P}<0.05$ ) and many other regions. According to correlation analyses, SINDVI is water-limited in arid and semi-arid regions, such as Middle East and central Asia, and temperature-limited in northern high-latitude.

Conclusions consistent with previous studies, our results suggest that anthropogenic activities are mainly responsible for increasing vegetation greenness in tailoring management measures (e.g., Ecological Engineering, the Grain to Green Project) of China and Europe, intensive farmed in Middle East. Coupling warming temperature and increasing precipitation, southeastern Asia and Russia showed an increasing trend in SINDVI. In general, climate factors were the dominant drivers of the variation in vegetation greenness in globally karst regions during research period.

Keywords: Vegetation greenness trends · SINDVI · Climate factors · Human activities · Global karst regions

\section{Introduction}

Karst physiognomy is created by mechanical erosion and chemical solubility (Liu et al. 2012), and there are substantive movement and large reciprocity of water and rock in karst areas. The global area of karst regions is approximately $2.2 \times 10^{7} \mathrm{~km}^{2}$, around $15 \%$ of global land areas (Falkowski et al. 2000). Karst dynamic system is characterized by the epikarst vegetation interaction, providing more than $25 \%$ of groundwater for global population (Cao et al. 2017). The karst ecosystem is particularly vulnerable mainly due to the alternation of seasonal drought and flood, soil erosion, surface subsidence, and rocky desertification (Huang et al. 2000; Yuan 1993). Under intensive anthropogenic disturbances and extreme climate changes, fragile karst terrains have been facing the threat of serious ecosystem degradation. This type of degradation often manifests as a reduction in vegetation cover and the consequence of soil erosion, is one of the most serious environmental problems in the world (Yuan 2000; Yue et al. 2010). Therefore, the dynamics of vegetation cover has been considered as an essential indicator of the ecosystem changes in karst regions (Kelly et al. 2011; Piao et al. 2015).

Vegetation is the main component of the terrestrial ecosystem and it plays an important role in global carbon cycle, water and energy balance. Under global climate change, how plant's photosynthesis responds to warming temperature and extreme climate events. Analysis vegetation greenness between temperature, precipitation are essential for designing policies to mitigate the passive impacts of extreme climate, anthropogenic activities on

61 the well-being of mankind and environment (Begue et al. 2011, Peters et al. 2012). Chen et al. (2019); De Jong 62 et al. (2013) have attempted to examined the causal factors responsible for the vegetation greenness by investi- 
gating the response of vegetation to climate changes, as represented by variables such as temperature and precipitation. however, different geological backgrounds may result in significant differences in soil and moisture regimes for the weathered crust, which restricts the spatial allocation of regional water and soil, as well as constrains the geochemical cycling processes of nutrients, leading to impacts on vegetation greenness (Florinsky and Kuryakova 1996; Seddon et al. 2016). As for the driving factors for spatiotemporal changes in vegetation, natural elements such as elevation precipitation and air temperature are usually consider to explore the spatial distribution of greening or browning trends (Chen and Pan 2010; Jiang et al. 2017; Ndayisaba et al. 2016). Furthermore, anthropogenic effect also have a significant impact on vegetation dynamics and distribution (Martínez and Gilabert 2009). Many previous studies have investigated the relationship between human practices and vegetation variations at different spatial scales (Liu et al. 2018; Sun et al. 2015; Tong et al. 2017). The vegetation in karst regions is an essential part of the global ecosystem and has strong spatial heterogeneity in different regions (Cao et al. 2017; Vermote et al. 2002). Understanding the characteristics of temporal and spatial variation in vegetation cover, and quantitatively analyzing the correlation between its changes with geographical and climate factors, is critical to study the relationship of vegetation, climate change and human activity to unveil the process of global environmental evolution and to predict future development trends (Aguilar et al. 2012; Pouliot et al. 2009).

The remote sensing (RS) technology have been widely applied in ecological research (Cabello et al. 2012; Feng et al. 2010; Pettorelli et al. 2005; Xie et al. 2008). Moderate Resolution Imaging Spectroradiometer (MODIS) data have been widely used since the launch of Terra platform in December 1999. The Normalized Difference Vegetation Index (NDVI) product from MODIS have been widely applied for vegetation research (Eisfelder et al. 2012; Fensholt et al. 2012). In recent decades, many studies have used NDVI data to monitor and evaluate variations in vegetation over different spatial and temporal scales, including research into vegetation phenology and terrestrial carbon cycle (Azzali and Menenti 2000), the characteristics of different crop species (Jakubauskas et al. 2002), forest fires (Jia et al. 2004; Leblon et al. 2001), the impacts of human activities on vegetation dynamics and distribution (Possingham et al. 2016), and vegetation cover characteristics and its response to climate change (Fensholt et al. 2009; Ma and Frank 2006; Pelkey et al. 2003; Wen et al. 2017). However, these impacts were rarely considered in the greenness trend of vegetation in global karst area, so as the influence of natural process and human activities effects on vegetation change. The study could provide foundations for the predicting of vegetation growth trends, ecosystem evolution and environmental change in the global karst regions. What's more, due to the seasonal variations in solar radiation and vegetation growth, Seasonally Integrated Normalized Difference Vegetation Index (SINDVI) works better than NDVI in reflecting inter-annual mutability and integrative vegetation cover trends (Sun et al. 2010). In addition, SINDVI, defined as the sum of NDVI values (NDVI > 0.1) in all time phases for each pixel during the growing season, can effectively eliminate the impact of regions with bare and sparse vegetation (Hope et al. 2003; Stow et al. 2003). SINDVI has been widely applied in exploring the land use and vegetation change, such as in Ejin Oasis (Hu et al. 2015), and the effect of vegetation change on albedo ( $\mathrm{Li}$ et al. 2018) and land surface temperature (Song et al. 2018). Based on previous research, we aimed to provide since the beginning of the 21th century information on the different vegetation in the global karst regions in this study. There were two main research objectives of the current study: (1) to investigate the overall trends of vegetation greenness and climate variables, applied Mann-Kendall to detect potential breaking points of SINDVI time series data, and (2) to analyzed changes in SINDVI and their relationships with climate factors and land cover change. 
Study area

106 Global karst regions, with a total area of $2.2 \times 10^{7} \mathrm{~km}^{2}$ were chooses as the study area in this research (Fig.

107 1). The World Karst Map V3.0 was obtained from Geography and Environmental Science, University of Auck-

108 land (https://www.fos.auckland.ac.nz/our_research/karst/index.html). To improve the accuracy of boundary in-

109 formation for the karst areas, the World Karst Map V3.0 data were integrated with detailed karst data in each

110 continent by Karst Scientific Data Center and is available from http://www.karstdata.cn. There is a prominent

111 karst zone around the world from western China through the Middle East to the Mediterranean and along the

112 coast of the western Atlantic. There are three major karst regions in the world: East Asia, the Mediterranean

113 coast and eastern America. In specific, these include southwestern China, northern Vietnam, central and south-

114 ern Europe, the central plateau of France, Ural in Russia, northeastern America, Cuba and Jamaica. According

115 to climatic conditions, karst areas be divided into 4 categories: the glacial karst area, Eurasian plate karst area,

116 North American plate karst area, and Gondwana continental karst area. Most karst regions have suffered from

117 a series of ecosystem damages, including rocky desertification, soil erosion, vegetation degeneration, and

118 productivity decline. In particular, Mexico, Middle East, Southeast Asia (Ford and Williams 2007), southwest

119 China (Jiang et al. 2014) and Mediterranean basin (Yassoglou 2000) are the most ecologically fragile areas in 120 the world (Kelly et al. 2011).

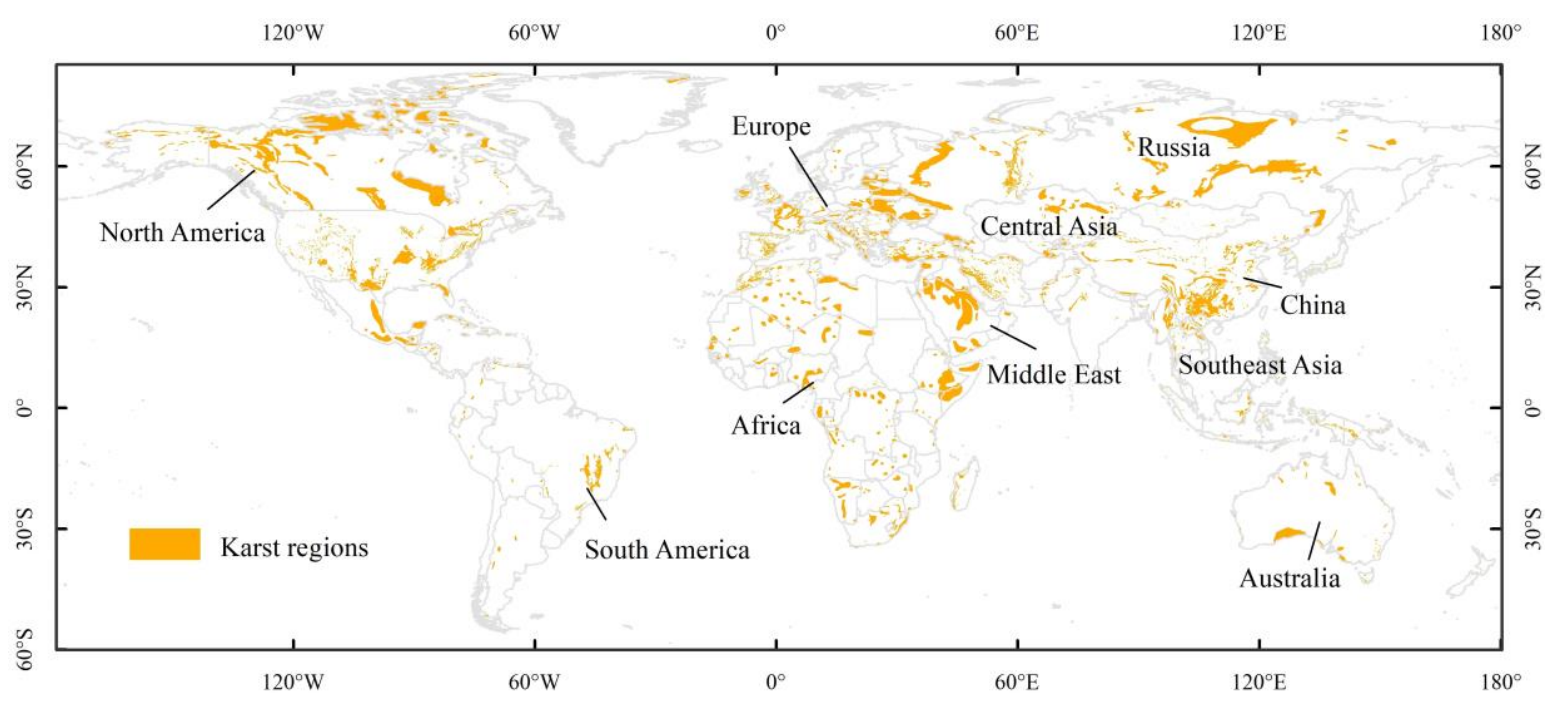

123 Datasets

124 Vegetation index data

125 This study selected the MODIS/Terra NDVI (collection 6) dataset, which was based on cloud-free composites 126 images from 16 days with a spatial resolution of $1 \mathrm{~km}$ (Wen et al. 2017). The NDVI data were supplied as a Level 1273 product projected onto a 0.05 -degree $(5600 \mathrm{~m})$ Climate Modeling Grid (CMG) with monthly temporal resolution, 128 provided by Land Processes Distributed Active Archive Center (LP DAAC), the NASA Earth Science Data and 129 Information System project, available from (https://doi.org/10.5067/MODIS/MOD13C2.006). 
SINDVI was defined as the sum of NDVI values greater than certain threshold ( 0.1 was selected in this study)

131 in all time phases throughout the year of each pixel (Hope et al. 2003; Ma and Frank 2006; Stow et al. 2003), it

132 was calculated by summing monthly NDVI values when NDVI $>0.1$ for each pixel as bellow:

$$
\mathrm{SINDVI}=\sum_{\mathrm{i}=0}^{\mathrm{i}=12} \mathrm{NDVI}_{\mathrm{i}}(\mathrm{NDVI}>0.1, \mathrm{i}=1,2, \ldots, 12)
$$

where $i$ represents the $i$ th month.

where $i$ means the $i$ th monthly NDVI. 10\% of the multiyear NDVI average of each pixel was set at a threshold

Meteorological data

Meteorological parameters including air temperature and precipitation were obtained from GLDAS_NOAH025_M data, Goddard Earth Sciences Data and Information Services Center (https://disc.gsfc.nasa.gov/datasets/GLDAS_NOAH025_M 2.1/summary?keywords=GLDAS), which were processed in monthly 0.25-degree resolution. The GLDAS air temperature was instantaneous observation per 3 hours, which firstly generated into monthly temperature by averaging, and then generated to the scale of annual temperature was in this study. While the GLDAS precipitation was the sum of rain and snow amount per 3 hours, which was firstly calculated to monthly precipitation and then accumulated to annual. GLDAS-2.1 data were archived in machine independent and self-describing NetCDF format. MATLAB R2016b was used to convert data format and synthesize meteorological data to a yearly scale.

\section{Land cover data}

To monitorand quantify the land cover change over the full time period in global karst regions, the Terra and Aqua combined MODIS (MCD12C1, V 6.0) data product (https://doi.org/10.5067/MODIS/MCD12Q1.006) were used. Maps of the International Geosphere-Biosphere Programme (IGBP), University of Maryland (UMD), and Leaf Area Index (LAI) classifications schemes are provided at annual scale at 0.05 degree (5,600 meter) spatial resolution for the entire globe, the dataset is available from 2001 to 2019.

Methods

\section{Reconstruct NDVI data}

The Mean Value Iteration filter (MVI), a simple and effective method was used to reconstruct NDVI and reduce the noise caused by the atmosphere water vapor and clouds. The reconstruction process can also eliminate some NDVI outliers in the original image, improving the homogeneity of each land cover type and spatial uniformity of NDVI image (Ma and Veroustraete 2006). A high quality of NDVI time series was calculated as follows:

$(\Delta T)$, when $\Delta i$ is greater than $\Delta T$, NDVI will be replaced by $\mathrm{NDVI}_{i}-\left(\mathrm{NDVI}_{i-1}+\mathrm{NDVI}_{i+1}\right) / 2$. Finally, when all $\Delta i$ are less than $\Delta T$ the iteration ended. 
Time series analyses

where $n$ is the cumulative number of years in the monitoring period; $i$ is the serial number of years and $i=1,2$, $\ldots 20$; and $X_{i}$ is the SINDVI, air temperature, or precipitation in the $i$ th year. Slopes $>0$ indicates that variables are increasing in $n$ years, while slopes $<0$ means a downward trend. The more the slope values are near to 0 , the much less changes are occurred in the trends (Jafary et al. 2018). To detect statistical significance of the variables trends in karst regions from 2001 to 2020, a Pearson correlation analysis was used and significance level was set to $0.05(\mathrm{P}<0.05)$ in this study.

The range was used to assess the magnitude of the changes. The value calculated for each pixel indicates the change between 2001 and 2020 .

$$
\text { Range }=\text { Slope } \times(n-1)
$$

where $n$ is the length of study periods.

\section{Mann-Kendall test}

Mann-Kendall analysis is a trend estimation method of time series based on nonparametric rank (Kendall 1975; Mann 1945), which is suitable for elastic processing of outliers (Lanzante 2015). The sequential version of the Mann-Kendal rank statistics can be performed using the following steps:

a. Replace original values of the series $x_{i}$ by their ranks $y_{i}$, arrange in ascending order.

b. The magnitudes of $y_{i}(i=2, \ldots, n)$ were compared with $y_{j}(j=1, \ldots, i-1)$. At each comparison, the number of cases $y_{i}>y_{j}$ was markede by $r_{i}$.

c. For the time series $\mathrm{X}$, which containing $n$ samples, a rank sequence $\left(\mathrm{S}_{m}\right)$ was first constructed as follows:

$$
\mathrm{S}_{m}=\sum_{i=1}^{m} r_{i}(m=2,3, \ldots, n)
$$

where $m$ is length of study periods; $S_{m}$ is the sum of all individual S statistics $\left(r_{i}\right)$ for all years

d. $\quad r_{i}$ is the cumulative number of the $i$ th sample when $y_{i}>y_{j}$ and it was defined as follows:

e. Considering that the time series are independent and random, the statistical UF is defined as follows:

$$
r_{i}=\left\{\begin{array}{ll}
1 & x_{i}>x_{j} \\
0 & x_{i} \leq x_{j}
\end{array}\right\}
$$

$$
\mathrm{UF}_{m}=\frac{\left[\mathrm{S}_{m}-\mathrm{E}\left(\mathrm{S}_{m}\right)\right]}{\sqrt{\operatorname{Var}\left(\mathrm{S}_{m}\right)}}(m=1,2,3, \ldots, n)
$$


f. $\quad \mathrm{E}(\mathrm{S} m)$ is the mathematical probabilities; and $\operatorname{Var}(\mathrm{S} m)$ is the variances. $\mathrm{E}(\mathrm{S} m)$ and $\operatorname{Var}(\mathrm{S} m)$ were cal-

196 culated as follows:

$$
\mathrm{E}\left(\mathrm{S}_{m}\right)=\frac{n(n-1)}{4}
$$

$$
\operatorname{Var}\left(\mathrm{S}_{m}\right)=\frac{n(n-1)(2 n+5)}{72}
$$

199 where $n$ is the number of observations. A positive value of $\mathrm{UF}_{m}$ indicates an increasing trend, which is a series

200 of positive statistics calculated by range $x_{1}, x_{2}, x_{3}, \ldots, x_{n}$. Subsequently, calculating the inverted sequence of 201 time series $\mathrm{X}\left(x_{n}, x_{n-1}, \ldots, x_{1}\right)$ by repeating the above process, to obtain the reverse statistical sequence $\mathrm{UB}_{m}$. If $202 \mathrm{UB}_{m}$ and $\mathrm{UF}_{m}$ intersect, their intersection may be a breakpoint $(\mathrm{P}<0.05)$.

\section{Correlation analysis}

204 In order to explorethe relationship between SINDVI and meteorological parameters (air temperature and precipitation), Pearson's correlation coefficients $(r)$ were calculated as follows:

$$
r_{x y}=\frac{\sum_{i=1}^{n}\left(x_{i}-\bar{x}\right)\left(y_{i}-\bar{y}\right)}{\sqrt{\sum_{i=1}^{n}\left(x_{i}-\bar{x}\right)^{2}} \sqrt{\sum_{n=1}^{n}\left(y_{i}-\bar{y}\right)^{2}}}
$$

where $\mathrm{r}_{x y}$ is the correlation coefficient between $x$ and $y$, and the values range from -1 to $1 ; x_{i}$ and $y_{i}$ are the values of the $i$ th year; $\bar{x}$ and $\bar{y}$ are their averages for 20 years.

Partial correlations were conducted to assess the dominant factor of each pixel. When estimating the partial correlation between temperature and SINDVI, the influence of precipitation will be considered as a constant.

211 For example, if the partial correlation coefficient between SINDVI and temperature was greater than the correlation coefficient between SINDVI and precipitation, it indicates that temperature had larger influence on

213 SINDVI. The partial correlation coefficients were calculated as follows:

$$
r_{y z \cdot x}=\frac{r_{y z}-r_{y x} r_{z x}}{\sqrt{\left(1-r_{y x}^{2}\right)\left(1-r_{z x}^{2}\right)}}
$$

where $r_{y z: x}$ is the partial correlation coefficient between $y$ and $z$ without consideration the influence of $x$; and $r_{x y}$ and $r_{x z}$ are the simple correlation coefficient between $\mathrm{x}$ and $\mathrm{y}$. For each pixel, the dominant by comparing the partial coefficient between NDVI and temperature or precipitation. Different significance levels were also set

218 for difference confidence interval (Extremely significant, $\mathrm{P}<0.01$; very significant, $\mathrm{P}<0.05$; significant, $\mathrm{P}<$ 2190.1 ; not significant, $0.1<\mathrm{P}<1)$.

\section{Results}

\section{Spatiotemporal variation in SINDVI}

222 Temporally, SINDVI showed an obvious increase trend during the period of $2001-2020$ in karst regions, 223 with an average of 3.99. While, there was large spatial heterogeneity (Fig. 2a), with the largest average SINDVI 224 values appeared in China and Europe. 
There were remarkable and widespread increment of SINDVI in the global karst areas during the research period (Fig. 2). In general, approximately $72.35 \%$ of the pixels showed upward trends. Meanwhile, there were also spatial differences between various regions. Especial the obvious disparity of the increasing trends appeared in tropical regions, subtropical humid regions and temperate regions. Notably, the increasing trend of the SINDVI in China was the most obvious, which increased 0.836 from 2001 to 2020 (Fig. 2b). In contrast, the decreasing trends of SINDVI mainly distributed in arid areas, such as -0.020 in Central Asia and -0.006 in South America respectively.

. The positive trends of SINDVI at low latitudes in the Northern Hemisphere were generally weaker than in middle and higher latitudes (Fig. 2b). In additional, SINDVI in the Northern Hemisphere growth 0.28, while

$$
\text { there was no significant trend in the Southern Hemisphere. }
$$
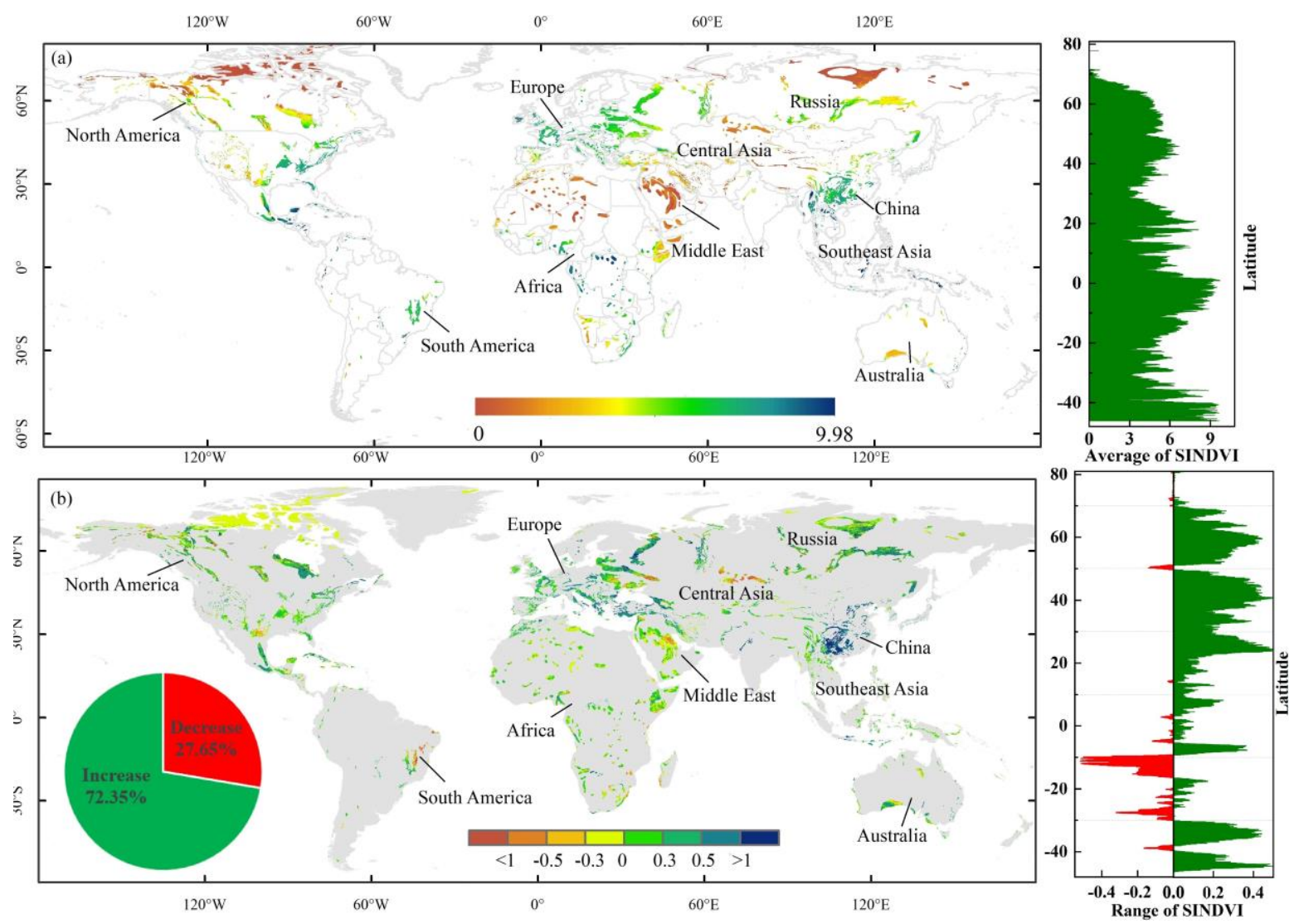

Fig. 2 Average (a) and change range (b) of the SINDVI during the period of 2001-2020 in the global karst areas. Pie chart at the lower left corner (b) shows the percentages of increasing and decreasing SINDVI pixels. Bar charts in the right show the latitudinal distribution of averages (a) and ranges (b) of SINDVI.

From 2001 to 2020, SINDVI in the global karst regions showed an increasing trend with large volatility (Fig. 3b) (slope $=0.011 / \mathrm{a}, \mathrm{P}<0.01)$. The sequential version of the Mann-Kendall tests was conducted to detect the breakpoints (Fig. 3a). The forward (UF) and backward (UB) statistics sequence curves intersected near the year of 2012, indicating that there was a significant change in SINDVI around 2012. Before the breakpoint, SINDVI exhibited a stronger positive trend with a rate of 0.011/a $(\mathrm{P}<0.05)$. However, after the breakpoint, the SINDVI exhibited a relatively weaker positive trend with a rate of $0.009 / \mathrm{a}(\mathrm{P}<0.05)$. In order to determine the patterns of inter-annual trends, we calculated the trends of both before the breakpoint (BBP) and after the breakpoint (ABP) for all regions and classified them into four categories (Fig. 4): increased in BBP but decreased in ABP, decreased in BBP but increase in ABP, upward trends in both BBP and ABP, and downward trends in both 
BBP and ABP. The results showed that the NINDVI in Australia, Middle East, Russia and South America showed climbed in BBP but decreased trends in ABP. China, North America, Europe, Africa and Southeast Asia showed sustained increasing trends from 2001 to 2020 at the rate of 0.034/a, 0.028/a, 0.011/a, 0.006/a and 0.005/a in BBP respectively. After that, with the exception of North America, the growth trends of the other three regions were stronger after the turning points. Central Asia showed a continuous downward trend, with the breakpoints in 2009, and the decreasing trends in ABP were weaker than those in BBP.
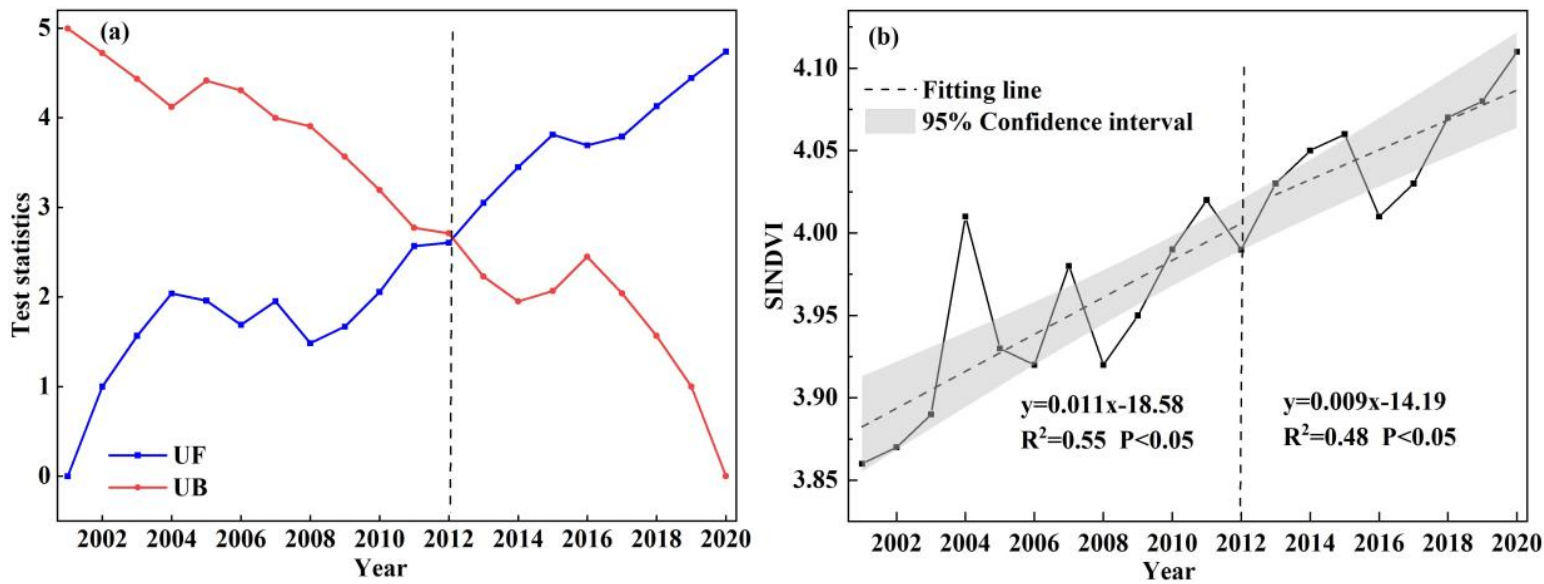

255 Fig. 3 Abrupt changes (a) and inter-annual variations (b) of SINDVI from 2001 to 2020. UF is the positive sequence of time series and UB is the negative sequence. UF and UB larger than 0 indicates increasing trends. The point where two curves intersect is the breakpoint $(\mathrm{P}<0.05)$.

Table 1 Change rates of SINDVI overall trend, BBP trend and ABP trend in global karst regions.

\begin{tabular}{ccccc}
\hline Karst regions & BP year & & Trend slope & ABP \\
\hline & & Allover & BBP & 0.041 \\
\cline { 3 - 4 } Africa & 2007 & 0.003 & 0.006 & -0.004 \\
Australia & 2012 & 0.006 & 0.022 & 0.039 \\
China & 2012 & 0.044 & 0.034 & -0.012 \\
Central Asia & 2009 & -0.020 & -0.039 & 0.024 \\
Europe & 2012 & 0.024 & 0.011 & -0.001 \\
Middle East & 2012 & 0.011 & 0.004 & 0.011 \\
North America & 2009 & 0.011 & 0.028 & -0.031 \\
Russia & 2011 & 0.004 & 0.029 & -0.009 \\
South America & 2006 & -0.006 & 0.012 & 0.018 \\
Southeast Asia & 2011 & 0.011 & 0.005 & \\
\hline
\end{tabular}

*: BP, BBP and ABP represent breakpoint, before the breakpoint and after the breakpoint, respectively.

261 Fig. 4 illustrated the spatial patterns of the trend in precipitation and temperature in global karst areas

262 during 2001 to 2020 . The annual average temperature showed an increasing trend of $0.06{ }^{\circ} \mathrm{C} / \mathrm{a}(\mathrm{P}<0.05)$

263 (Fig. 4a). Spatially, all the karst regions experienced air temperature warming trends, particularly in Africa 
and Middle East where the magnitude of the temperature trend exceeds $2{ }^{\circ} \mathrm{C}$ during research period. Conversely, precipitation experienced slightly decreased at the rate of $-0.36 \mathrm{~mm} / \mathrm{a}(\mathrm{P}>0.05)(\mathbf{F i g} . \mathbf{4 b})$, only

266 China and Southeast Asia have increasing trends. The maximum of temperature and precipitation appeared 267 in 2010, which trends were in good agreement with long-term trends in precipitation in previous study of 268 Adler et al. (2017).
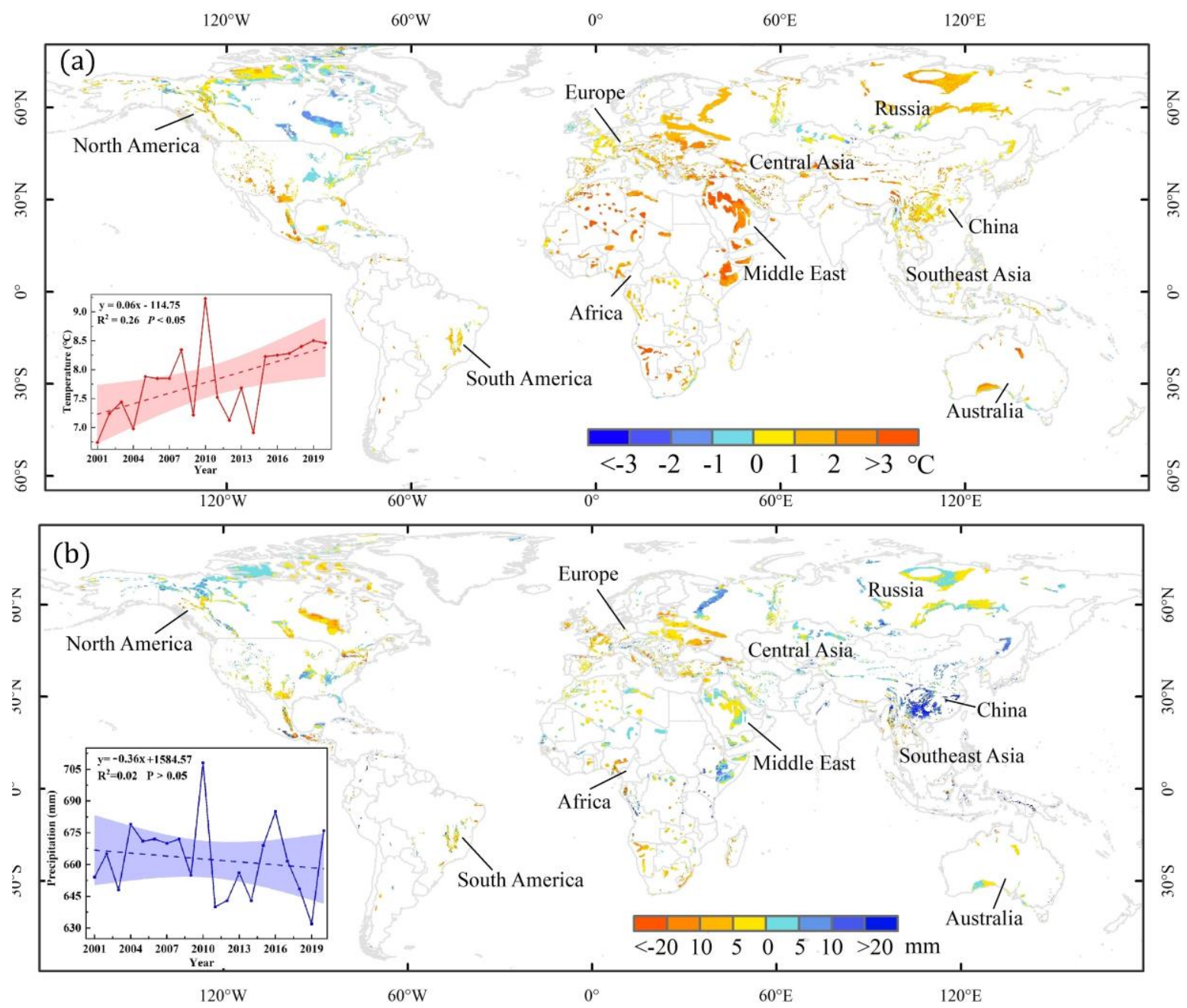

Fig.4 Spatial distribution of change range in (a) temperature and (b) precipitation. Line chart in lower left corner illustrated the inter-annual variations in air temperature and precipitation in global karst regions from 2001 to 2020. 
Table 2. Overall changes of the SINDVI, air temperature and precipitation in global karst regions during the period of 2001-

2792020.

\begin{tabular}{cccc}
\hline Karst regions & SINDVI & Temperature $\left({ }^{\circ} \mathrm{C}\right)$ & Precipitation $(\mathrm{mm})$ \\
\hline Africa & 0.057 & 2.27 & -3.87 \\
Australia & 0.114 & 1.52 & -40.37 \\
Central Asia & -0.380 & 0.50 & 49.30 \\
China & 0.836 & 1.40 & 188.32 \\
Europe & 0.456 & 1.46 & -49.56 \\
Middle East & 0.209 & 2.46 & -21.09 \\
North America & 0.209 & 0.27 & -21.50 \\
Russia & 0.076 & 1.25 & 6.12 \\
South America & -0.114 & 1.14 & -19.94 \\
Southeast Asia & 0.209 & 0.75 & 220.47
\end{tabular}
coefficients were calculated for each pixels (Fig. 5). About 21.12\% of SINDVI pixels was affected by precipi-

282 tation $(\mathrm{P}<0.05)$ in global karst regions. (Fig. 5a). Correlation coefficients greater than 0.5 mainly occurred in 283 Middle East peninsula, Mexico, Southwest China, Southern Australia and Southern Africa (Fig. 5c). Approxi284 mately $15.22 \%$ pixels indicated that temperature have significant influenced on the variation of SINDVI (Fig. 285 5b), with $r$ values larger than 0.5 were mainly distributed in Central Eurasia, Eastern Mediterranean, Eastern and Northwest Canada, Southwestern China and Eastern United States (Fig. 5d). 

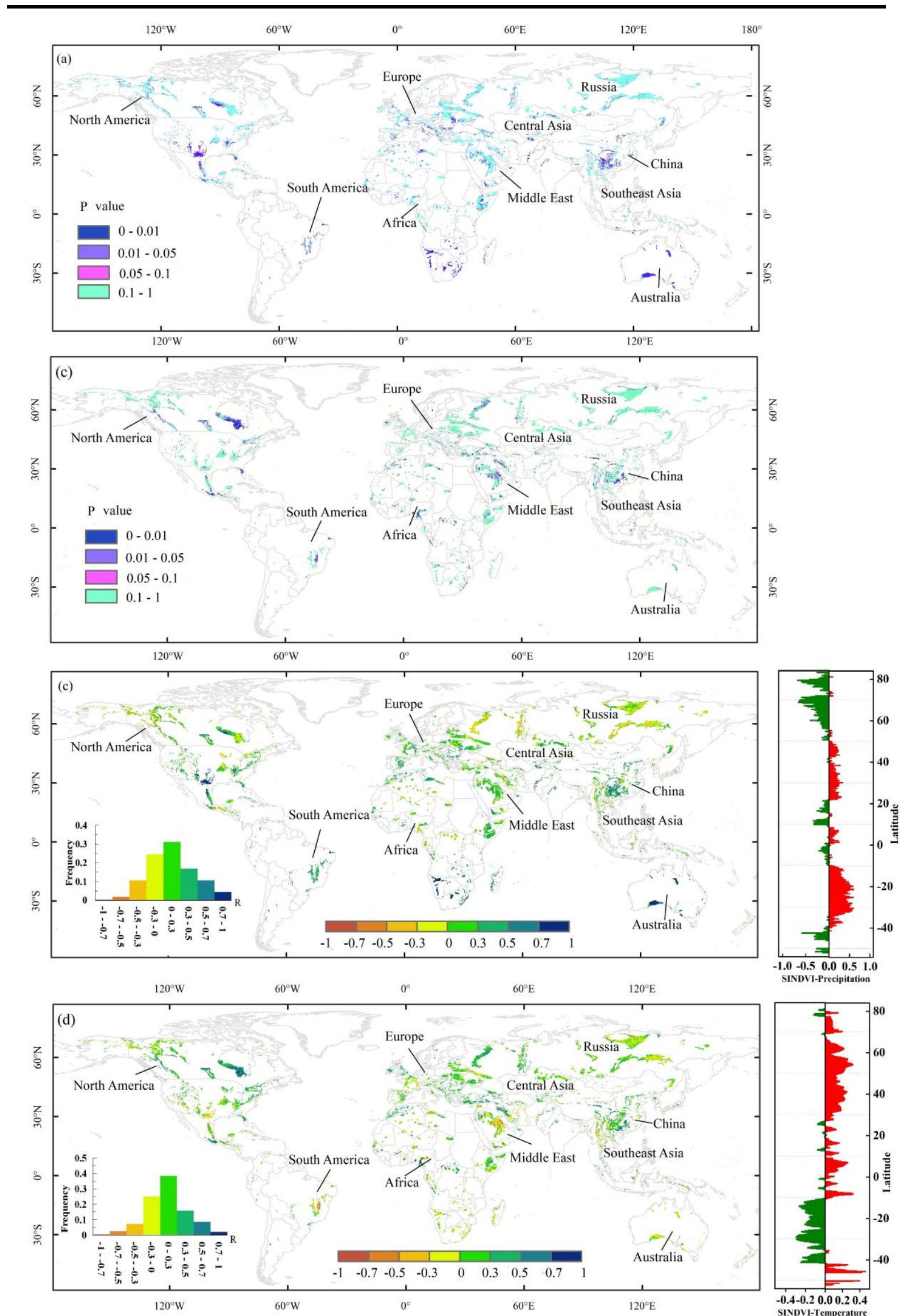

Fig. 5 Spatial significance levels of correlation (a) between SINDVI and precipitation, (b) between SINDVI and temperature from 2001 to 2020 in global karst areas. (c) The correlation coefficients between SINDVI and precipitation, and (d) between 
SINDVI and temperature. Non-vegetation regions were removed. Histogram in the left is the frequency distribution of correlation coefficients of the pixel count.

The partial correlation coefficient was calculated for each pixel to determine the main factor of SINDVI change (Fig. 6), wherein only $21.06 \%$ of the areas are significance $(\mathrm{P}<0.05)$. The karst regions of several different regions have analyzed below.

In the arid regions in the Southern Hemisphere, including Australia and South Africa, SINDVI dynamic were synergistic with precipitation change (Fig. 6). In near the equator, where the precipitation is abundant throughout the year, temperature seems to play a powerful role in the fluctuation of SINDVI.

In the high latitude areas of the Northern Hemisphere, temperature acted as the dominant factor affecting the SINDVI. All of the rising temperature, stronger photosynthesis and longer growth season, facilitated the plant growth vigorously and then promoted SINDVI..
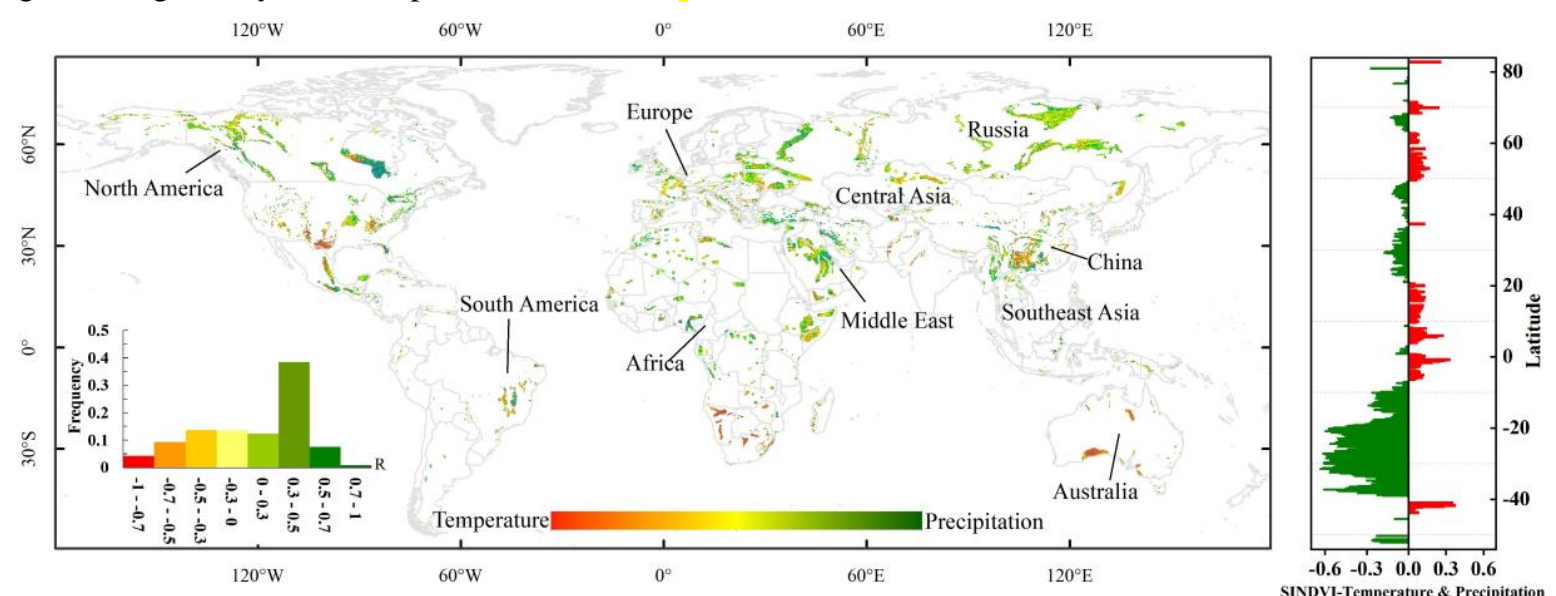

Fig. 6 Partial correlation coefficient of SINDVI with temperature and precipitation in global karst areas. The green color represents the area where precipitation is the main factor of SINDVI change; while the red color represents the area where temperature is the dominant factor. Histogram in the lower left corner is the frequency distribution of correlation coefficients.

306 Trend of land cover change in karst regions

307 Since we interested in changes in type of vegetation cover, and take into account only five land uses in the 308 karst regions: cropland, forest, shrub land, grassland and bare land the dominant types in global karst regions 309 were grassland, and forest. Between 2001 and 2019, grassland area has increased from $438.986 \times 10^{4} \mathrm{~km}^{2}$ to $310443.810 \times 10^{4} \mathrm{~km}^{2}$ with a rate of $0.2868 \times 10^{4} \mathrm{~km}^{2} / \mathrm{a}$, cropland area has a slightly increasing at the rate of 0.0936 $311 \times 10^{4} \mathrm{~km}^{2} / \mathrm{a}$. In contrast, the shrub land, forest and bare land exhibited decreasing trends with rates of -0.1103 $312 \times 10^{4} \mathrm{~km}^{2} / \mathrm{a},-0.1598 \times 10^{4} \mathrm{~km}^{2} / \mathrm{a}$ and $-0.0771 \times 10^{4} \mathrm{~km}^{2} / \mathrm{a}$, respectively (Fig. 7). 


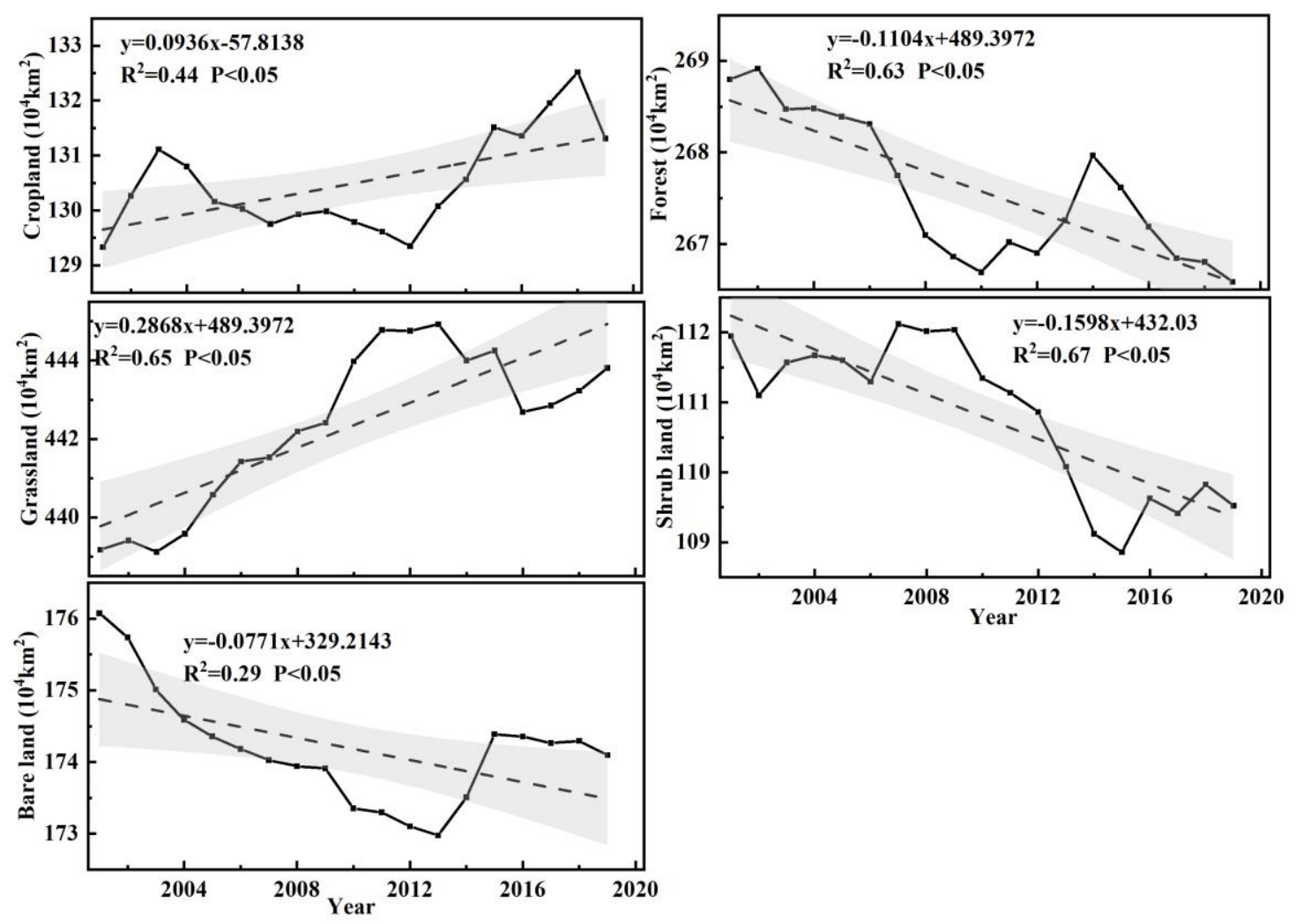

Fig. 7 Temporal changes of land cover types in global karst regions from 2001 to 2019.

315 At the regional scale, the various land cover types undergo different changes at different regions, and a detailed statistical analysis of the five main land cover types were performed for ten karst regions (Fig. 8). The 317 cropland area reduced in Europe, China, Africa and Southeast Asia. In terms of forest, with exception of Russia, 318 Africa, North America, South America and Middle East, all other regions showed increasing trends. In addi319 tional, most regions experienced the disappearing of shrub land excepted three regions (Central Asia, Australia 320 and Southeast Asia).For grasslands, besides five regions (Central Asia, Australia, Europe, Middle East and 321 Southeast Asia), all other regions showed upward trends. Regarding bare land, China, Africa and North America 322 remarkably dropped, conversely, while Middle East has positive trend, and other regions have no visible 323 changes. 

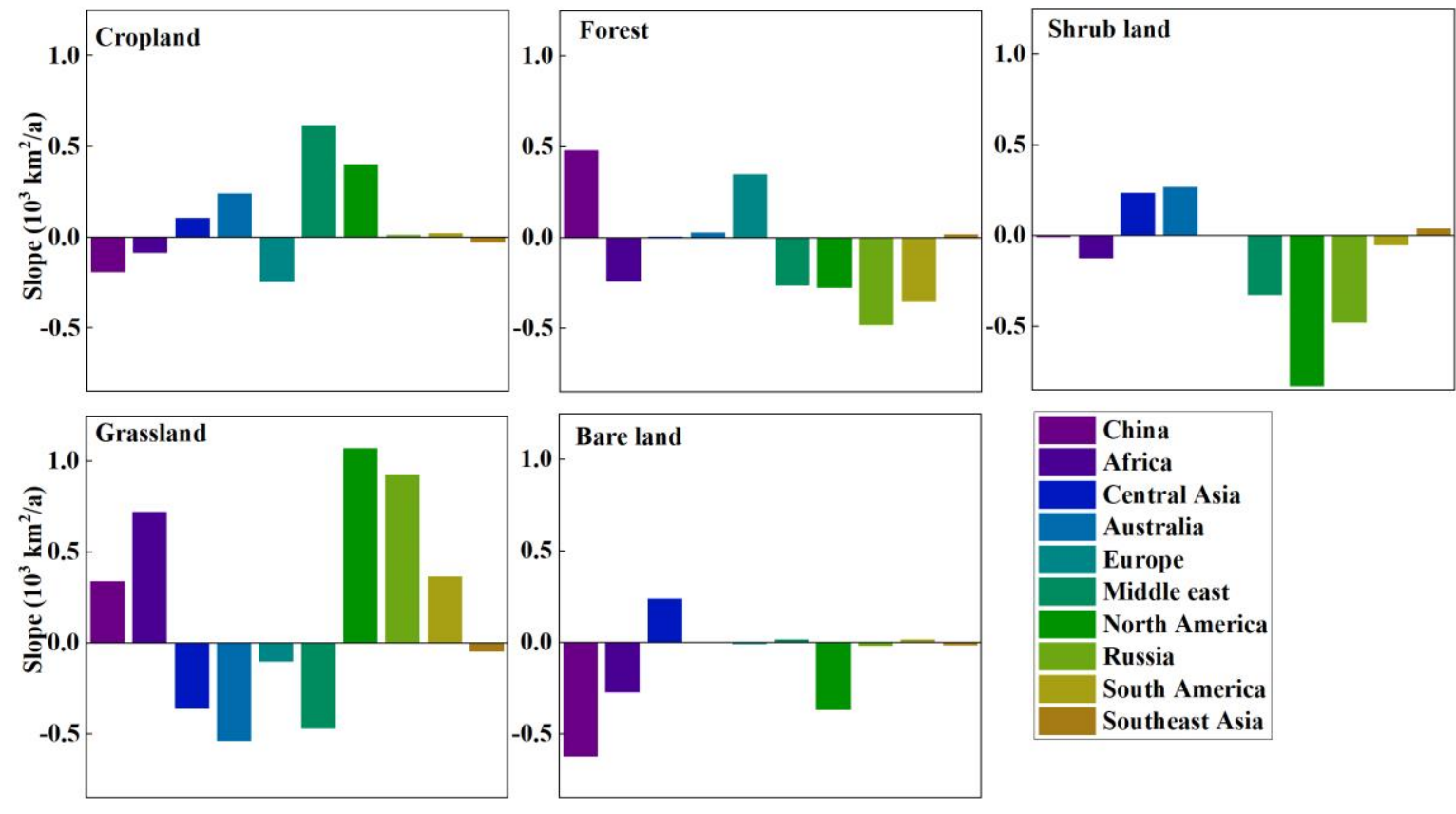

Fig. 8 Change rates of the land cover types in different karst regions from 2001 to 2019

\section{Discussions}

Our results indicate that the spatio-temporal variations of SINDVI over the global karst regions show a greening trend during 2001-2020 (slope $=0.011 / \mathrm{a}, \mathrm{P}<0.01$ ), which is consistent with previous study (Zhang et al., 2017, Piao et al. 2020). There are two distinct periods with growing trends in SINDVI, in the first period (Fig. 3), SINDVI has significantly increased from 2001 to 2012 (slope $=0.011 / \mathrm{a}, \mathrm{P}<0.01$ ), and then relatively weaker grown from 2012 to 2020 (slope $=0.009 / \mathrm{a}, \mathrm{P}<0.01$ ). Changes in the latter period is largely contributed by the browning vegetation which occurred in Australia and Middle East after 2012, and Russia after 2011 respectively. Which offset the greening trend before 2012 in other karst regions, this finding also consistent with previous reports (Long et al. 2018, Piao et al. 2020).

This study also indicates that climate change is the most important factor influencing vegetation dynamics in karst regions (Fig. 5), which is in a good agreement with previous results (Piao et al. 2014).During the research period, two meteorological factors (air temperature and precipitation) had significantly positive relationships with the inter-annual SINDVI variation in the global karst regions, indicating that the increase of temperature and precipitation could promote the growth of vegetation.

Despite the positive correlation between temperature and SINDVI in most karst areas of the Northern Hemisphere, including China, Europe and North America, the significant negative correlation also appeared in most dry areas and the middle-latitude areas, such as South Africa, Southern Australia, Middle East (Fig. 5d). In the dry areas, the persistent warming and decreasing of precipitation can seriously aggravate the water deficit and evapotranspiration loss, bringing heavy damage to plant growth (Zhou et al. 2015). Because of obvious spatiotemporal differences, this study chosen several regions with obvious variation of SINDVI to explore the related in global karst areas. Increasing trends in the SINDVI

Vegetation in the karst areas of China has increased in the last decade (Fig.2b). The relationship between SINDVI and temperature was closer than that between SINDVI and precipitation (Fig. 6). This might be related 
to the location of Southwestern China, which is the subtropical monsoon climate zone, with adequate precipitation. Therefore, small changes of precipitation may not cause seriously change on vegetation growth (Lai et al. 2020; Hou et al. 2015; Zhao et al. 2017). In addition, the dual hydrological structures of surface and underground in karst region in Southwest China lead to drainage of precipitation through leakage and runoff (Tong et al. 2016), indicating the precipitation has limited effect of vegetation growth. As for the reason behind the greening in this area, on the one hand, governments have taken some effective measures (e.g., relocation and ecological migration) to reduce land abandonment and land degradation caused by the outflow of rural population (Chen et al. 2019). On the other hand, ecosystem restoration projects (for example, the Grain to Green Project, the Karst Rocky Desertification Restoration Project, and the Natural Forest Protection Project) have been implemented (Mueller et al. 2014; Tong et al. 2018; Zhang 2008) are considered an important factor in turning green, especially in China since 2008.

The similar political decisions appeared in Europe, the afforestation and forest management have accelerated the growth of vegetation (Naudts et al. 2016), causing the dramatic increase in the forest area of $0.3485 \times 10^{3}$ $\mathrm{km}^{2} / \mathrm{a}$ (Fig. 8) and contributing to the upward trend in the SINDVI. Furthermore, the rising temperature (Range $=1.46^{\circ} \mathrm{C}$ ) might have promoted the growth of vegetation, which may explain the greening trend. Previous study indicated that the positive effect of meteorological parameters change in the northern high latitudes were attributed to nitrogen deposition and $\mathrm{CO}_{2}$ concentration in the boreal forests, other factors including enhanced photosynthesis and prolonged growing seasons (LeBauer and Treseder 2008; Liu et al. 2015; Menzel et al. 2006; Xu et al. 2013). In central and northeastern America, the increasing temperature was the dominant factor affected the SINDVI (Fig. 5d), this upward trend was contributed to vegetation propagation caused by global warming (Zhu et al. 2016). Moreover, agricultural fertilization and irrigation would also have a significant impact on the trend of SINDVI dynamics (Neigh et al. 2008) In contrast, the effect of precipitation was stronger than that of temperature in southern North America (Fig. 6). Fig. 3 shows that the BP of the inter-annual variation in SINDVI occurred in 2012, the SINDVI showed an increasing trend with a slope of 0.028/a before breaking point (BBP); while, the upward trend was relatively slight (slope $=0.011 / \mathrm{a}$ ) after the breakpoint (ABP). The extreme climate and the cool winters in 2009/2010, 2010/2011, and 2013/2014 in North America led to anomalous vegetation growth (Yu and Zhang 2015).

For arid and semi-arid areas, the land use type is mainly savanna and desert, although the trend in vegetation cover is similar to that of global level, their extents of changes are differently. Precipitation is characterized by regular seasonal drought and large inter-annual fluctuation. Due to the non-irrigated crops and natural ecosystems mainly depend on soil moisture produced by snow melt in spring and seasonal rainfall (Baldocchi et al. 2004; Zaitchik et al. 2007), there is large inter-annual fluctuation in the vegetation coverage (Fig. 4). The drought episodes that struck the Middle Eastern countries in 2007-2009 were the worst drought events to impact the region in more than 60 years (Villa et al. 2014). What's more, both the dominant impact of the lower precipitation and the climbed temperature (Table. 2) in this period provide the sufficient conditions of extreme drought in this area. Nonetheless, a fact that a faster recovery of cropland in intensive agricultural areas, these greening trends were due to farming in the North Iraq and Turkey for which groundwater and desalinated seawater were used (Rousta et al. 2020). In the low latitudes, except for temperature and precipitation, solar radiation is also a limiting factor (Nemani et al. 2003). In Southeast Asia the NDVI product may include some inaccuracies. We applied the Maximum Value Composite (MVC) method to reduce the outliers of data, but the selected maximum value is not always the nadir value that tends to overestimate NDVI values (Huete et al. 
2002). Moreover, the NDVI value saturates easily under high vegetation coverage and cannot sensitively monitor the changes in vegetation growth (Wang et al. 2003). These issues associated with NDVI also influence the accuracy of the correlations.

In order to evaluate the temporal evolution of low vegetation areas when NDVI $<0.1$ (Fig. 9), we found that Middle East, Arctic tundra and the Sahara have greening trends, while central Asia shew a browning trend. These results, at least in part, are in agreement with previous studies (Berner et al. 2020, Piao et al. 2020 Rousta et al. 2020)

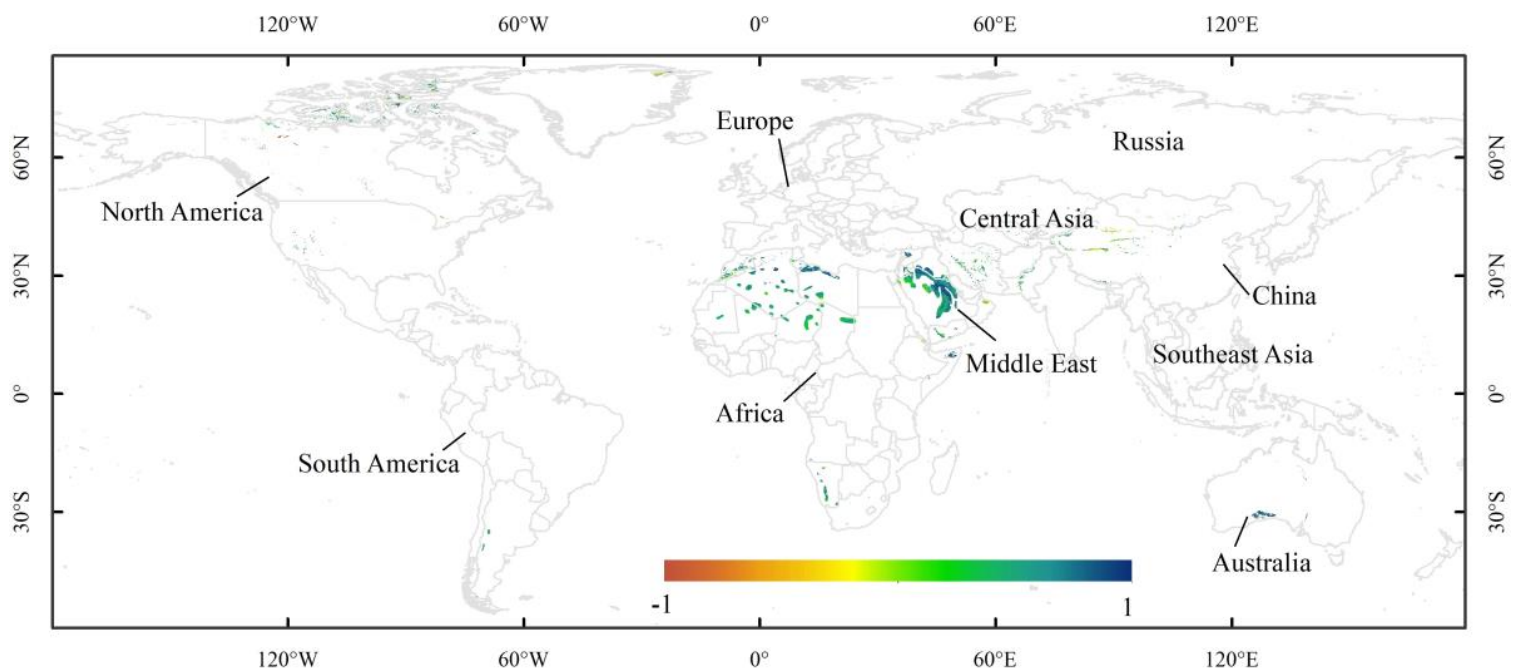

Fig. 9 Spatial distribution of change range of NDVI $<0.1$.

Decrease trends in SINDVI

Located in the hinterlands of the Eurasian continent, Central Asia is one of the driest areas in the world (Cihlar et al. 1997) with low vegetation coverage. Most area is desert in this region besides Tajikistan and Kyrgyzstan which are predominantly mountainous. The variation of SINDVI indicates that vegetation degradation mainly occurred in northern Kazakhstan, southern Tajikistan and southwestern Kyrgyzstan. The spatial distribution of temperature from 2001 to 2020 showed a significance warming trend (Fig. 4), although the slightly increasing trend in precipitation, sufficient sunlight and solar energy resources in these domains are abundant than other places, resulting in annual precipitation less than annual evapotranspiration; thus, Excessive evapotranspiration is the hinge process of soil moisture loss and leads to the shallow roots of desert plants to withered (Li et al. 2015; Yuan et al. 2017). In the drought periods, moisture insufficiency inhibited the growth of vegetation and reduced photosynthesis of plants (Stocker et al. 2019; Zhang et al. 2012).

This study found the sharply decreasing trend of the forest cover of Russia, Africa, North America, South America and Middle East (Fig. 8), mainly caused by fire, diseases or even over-logging (for example, large areas tree mortality in North America owning to plant disease and insect pests (Yang, et al. 2017); Middle East and South America experienced a widespread deforestation and fire (Aparna et al. 2020; Qin et al. 2017)). This study also found that the increment of grassland and cropland areas in these regions make contribution to the

415 positive trend of SINDVI, which is consistent with the findings that cropland land increase in some regions and 416 that the increase in vegetation greenness occurred in regions of intensive agricultural activities (Hansen et al. 417 2014; Lamchin et al. 2020). 
In the Northern Hemisphere, vegetation growth was mainly affected by temperature, while precipitation was the dominant factor to the change of vegetation greenness in the Southern Hemisphere. The karst areas of South America, which are mainly in the east of Brazil. According to Table 2, SINDVI here showed a downward trend, and the vegetation coverage in this region did not couple with temperature and precipitation. This lack of correlation is attributed to heavy human intervention. Under pressure from human society, land use change is increasingly threatening tropical rainforest area (Dirzo and Raven 2003). The quick transformation of forests into agricultural, timber production and other uses has produced a vast and human dominated landscape, which will bring immeasurable destruction to the rainforest (Gardner et al. 2009, Hansen et al. 2014). However, some studies have shown that the occurrence of extreme weather in recent years has aggravated the natural disasters, such as the severe droughts occurred in Brazil in 2007 (Cunha et al. 2019).

This study aimed to observe the impact of meteorological parameters change and human environmental protection policies on vegetation dynamic from 2001 to 2020. Our results indicate that the karst ecosystem is particularly vulnerable to the alternation of seasonal drought and flood. Especially in the 21th century, under intensive anthropogenic activities and climate changes (extreme weather events), fragile karst terrains have been

432 facing the threat of serious ecosystem degradation. This study assesses the important issues including anthro433 pogenic disturbance and climate change in karst area on global or regional scales. In particular, we have elaborated the impact of climate change in Southwest China, human activities were the dominate factor of vegetation greening, while in 2009/2010, there was a downward trend in SINDVI due to a period of extreme drought ( $\mathrm{Li}$ et al. 2019; Zhao et al. 2017). Many previous studies also have confirmed that abnormal cyclone in the western North Pacific during an El Niño period resulted in a severe reduction in precipitation in Southwest China in the autumn of 2009 (Zhang et al. 2013). Climate change has caused large variations in seasonal and annual precipitation and temperature, both locally and globally (Fernández et al. 2014). Especially in the recent decades, drought occurred with longer durations, greater intensities and more frequently, with the serious impact on karst ecosystem (Trenberth et al. 2014; Williams et al. 2015). Deep rooting plant access to bedrock water storage and groundwater is an importance feature to plant survival in drought environments (Ding et al. 2020, Wang et al. 2019). For example, the effects of droughts have been widely reported in the karst areas in the United States (Ganguli and Ganguly 2016), Europe (Spinoni et al. 2017) and central equatorial Africa (Hua et al. 2016). A better knowledge of the dynamics of vegetation greenness and it responses to extremely climate is an essential process in understanding current situations and project future changes. The current study is mainly about the global karst vegetation change, with focuses on several fragile karst regions. The results provide scientific evidence for the protection of fragile karst ecosystem, while detailed studies in each karst area are still needed.

\section{Conclusions}

In summary, this study assessed spatiotemporal variations in vegetation cover by estimating global SINDVI trends for karst region. On a global karst scale, inter-annual SINDVI of the karst regions from 2001 to 2020 exhibited an upward trend by 0.011/a. Temperature and precipitation had prominent effect on inter-annual changes in SINDVI with large spatiotemporal heterogeneities. In dry areas such as Central Asia, persistent warming coupled with decreasing precipitation caused serious water deficit and great evapotranspiration loss, thus affected the growth of vegetation. However, in some middle and high latitude areas, warming temperature was considered to be the main reason for greening trends, such as in northern Eurasia and northern North America. In addition to studying climate factors (temperature and precipitation), this study assessed anthropogenic 
activities (e.g., Ecological Engineering, the Grain to Green Project) also have significant impact on the varia-

459 tions in SINDVI

460 Acknowledgments In this study, we archived multi-resource datasets from different data centers. The data 461 include the MODIS NDVI, GLDAS-2.1data, land cover data and population density data. They were provided 462 by USGS, ESA and SEDAC. The authors express their gratitude for the data sharing of above datasets.

463 Author Contributions Conceptualization, Jing Huang and Mingguo Ma; Data curation, Xuguang Tang; For464 mal analysis, Jing Huang, Yuqing Huang and Xuguang Tang; Funding acquisition, Mingguo Ma; Methodology, Jing Huang, Zhongxi Ge and BinfeiHao; Resources, Mingguo Ma; Software, Peiyu Lai, BinfeiHao and

466 Zengjing Song; Validation, Zhan Shi; Writing - original draft, Jing Huang and Zhongxi Ge; Writing - review 467 \& editing, Jing Huang, Yuqing Huang, Peiyu Lai, Hong Yang and Mingguo Ma.

468 Funding This work was jointly supported by supported by the National Natural Science Foundation of China projects (grant numbers: 41830648 and 41771453), the Fundamental Research Funds for the Central Universities of China (Grant No. XDJK2015C007), National Key Technology R\&D Program of China (grant number: 2016YFC0500106).

Conflicts of Interest The authors declare no conflict of interest.

\section{References}

Adler, R.F., Gu, G., Sapiano, M. et al. (2017) Global Precipitation: Means, Variations and Trends During the Satellite Era (1979-2014). Surv Geophys 38: 679-699. https://doi.org/10.1007/s10712-017-9416-4.

Aguilar C, Zinnert JC, Polo MJ, Young DR (2012) NDVI as an indicator for changes in water availability to woody vegetation. Ecol Indic 23: 290-300. https://doi.org/10.1016/j.ecolind.2012.04.008.

Aparna R. Phalke, Mutlu Özdoğan, Prasad S. Thenkabail, Tyler Erickson, Noel Gorelick, Kamini Yadav, Russell G. Congalton (2020) Mapping croplands of Europe, Middle East, Russia, and Central Asia

Azzali S, Menenti M (2000) Mapping vegetation-soil-climate complexes in southern Africa using temporal Fourier analysis of NOAA-AVHRR NDVI data. Int $\mathbf{J}$ Remote Sens 21: 973-996. https://doi.org/10.1080/014311600210380.

Baldocchi DD, Xu LK, Kiang N (2004) How plant functional-type, weather, seasonal drought, and soil physicalproperties alter water and energy fluxes of an oak-grass savanna and an annual grassland. 
Begue A, Vintrou E, Ruelland D, Claden M, Dessay N (2011) Can a 25-year trend in Soudano-Sahelian vegetation dynamics be interpreted in terms of land use change? A remote sensing approach. Glob Environ Chang 21: 413-420. https://doi.org/10.1016/j.gloenvcha.2011.02.002.

Berner, LT, Massey, R, Jantz, P et al. (2020) Summer warming explains widespread but not uniform greening in the Arctic tundra biome. Nat Commun 11: 4621. https://doi.org/10.1038/s41467-020-18479-5.

Cabello J, Fernández N, Alcaraz-Segura D, Oyonarte C, Piñeiro G, Altesor A, Delibes M, Paruelo JM (2012) The ecosystem functioning dimension in conservation: insights from remote sensing. Biodivers Conserv 21: 3287-3305. https://doi.org/10.1007/s10531-012-0370-7.

Cao J, Jiang Z, Yuan D, Xia R, Zhang C (2017) The progress in the study of the karst dynamic system and global changes in the past 30 years. Geol in China 44: 874-900.

Chen C, Park TJ, Wang XH, Piao SL, Xu B, Chaturvedi RK, Fuchs R, Brovkin V, Ciais P, Fensholt R, Tømmervik H, Bala G, Zhu ZC, Nemani RR, Myneni RB (2019) China and India lead in greening of the world through land-use management. Nat Sustain 2: 122-129. https://doi.org/10.1038/s41893-0190220-7.

Chen X, Pan W (2010) Relationships among phenological growing season, time-integrated normalized difference vegetation index and climate forcing in the temperate region of eastern China. Int J Climatol 22: 1781-1792. https://doi.org/10.1002/joc.823.

Cihlar J, Ly H, Li ZQ, Jing C, Pokrant H, Huang FT (1997) Multitemporal, multichannel AVHRR data sets for land biosphere studies-Artifacts and corrections. Remote Sens Environ 60: 35-57. https://doi.org/10.1016/s0034-4257(96)00137-x.

Cunha APMA, Zeri M, Leal KD, Costa L, Cuartas LA, Marengo JA, Tomasella J, Vieira RM, Barbosa AA (2019) Extreme Drought Events over Brazil from 2011 to 2019. Atmos 10. https://doi.org/10.3390/atmos10110642.

De Jong R, Schaepman ME, Furrer R, De Bruin S, Verburg PH (2013) Spatial Relationship Between Climatologies and Changes in Global Vegetation Activity. Glob Chang Biol 19: 1953-1964. https://doi.org/10.1111/gcb.12193.

Dirzo R, Raven PH (2003) Global state of biodiversity and loss. Annu Rev EnvironResour 28: 137-167. 
Ding YL, Nie YP, Chen HS, Wang KL, Querejeta JI (2021) Water uptake depth is coordinated with leaf water potential, water-use efficiency and drought vulnerability in karst vegetation. New Phytol 229: 13391353. https://doi.org/10.1111/nph.16971.

Eisfelder C, Kuenzer C, Dech S (2012) Derivation of biomass information for semi-arid areas using remotesensing data. Int J Remote Sens 33: 2937-2984. https://doi.org/10.1080/01431161.2011.620034.

Falkowski P, Scholes RJ, Boyle E, Canadell J, Canfield D, Elser J, Gruber N, Hibbard K, H?Gberg P, Linder S (2000) The global carbon cycle: a test of our knowledge of earth as a system. Science 290: 291-296. https://doi.org/10.1126/science.290.5490.291.

Feng X, Fu B, Yang X, Lü Y (2010) Remote sensing of ecosystem services: An opportunity for spatially explicit assessment. Chinese Geogra Sci 20: 522-535. https://doi.org/10.1007/s11769-010-0428-y.

Fensholt R, Proud SR, Simon R (2012) Evaluation of Earth Observation based global long term vegetation trends - Comparing GIMMS and MODIS global NDVI time series. Remote Sens Environ 119: 131147. https://doi.org/10.1016/j.rse.2011.12.015.

Fensholt R, Rasmussen K, Nielsen TT, Mbow C (2009) Evaluation of earth observation based long term vegetation trends - Intercomparing NDVI time series trend analysis consistency of Sahel from AVHRR GIMMS, Terra MODIS and SPOT VGT data. Remote Sens Environ 113: 1886-1898. https://doi.org/10.1016/j.rse.2009.04.004.

Fernández ME, Gyenge JE, Varela S, De Urquiza M (2014) Effects of the time of drought occurrence within the growing season on growth and survival of Pinus ponderosa seedlings. Trees 28: 745-756. https://doi.org//10.1007/s00468-014-0986-1.

Florinsky IV, Kuryakova GA (1996) Influence of topography on some vegetation cover properties. Catena 27: 123-141. https://doi.org/10.1016/0341-8162(96)00005-7.

Ford D, Williams P (2007) Karst Hydrogeology and Geomorphology. John Wiley \& Sons Ltd, England.

Ganguli P, Ganguly AR (2016) Space-time trends in U.S. meteorological droughts. JHydrol: Reg Stud 8: 235259. https://doi.org/10.1016/j.ejrh.2016.09.004.

Gardner TA, Barlow J, Chazdon R, Ewers RM, Harvey CA (2009) Prospects for tropical forest biodiversity in a human-modified world. Ecol Lett 12: 561-582. https://doi.org/10.1111/j.1461-0248.2009.01294.x. 
Hansen M, Potapov P, Margono B, Stehman S, Turubanova S, Tyukavina A (2014) Response to comment on "High-resolution global maps of 21st-century forest cover change". Science 342: 850-853. https://doi.org/10.1126/science.1248817.

Hope AS, Boynton WL, Stow DA, Douglas DC (2003) Interannual growth dynamics of vegetation in the Kuparuk River watershed, Alaska based on the Normalized Difference Vegetation Index. Int J Remote Sens 24: 3413-3425. https://doi.org/10.1080/0143116021000021170.

Hou WJ, Gao JB, Wu SH, Dai E (2015) Interannual Variations in Growing-Season NDVI and Its Correlation with Climate Variables in the Southwestern Karst Region of China. Remote Sens 7: 11105-11124. https://doi.org/10.3390/rs70911105.

Hu XL, Lu L, Li X, Wang JH, Lu XG (2015) Ejin Oasis Land Use and Vegetation Change between 2000 and2011: The Role of the Ecological Water Diversion Project. Energies 8: 7040-7057. https://doi.org/10.3390/en8077040.

Hua W, Zhou L, Chen H, Nicholson SE, Jiang Y (2016) Possible causes of the Central Equatorial African longterm drought. Environ Res Lett 11: 124-138. https://doi.org/10.1088/1748-9326/11/12/124002.

Huang MT, Piao SL, Ciais P, Peñuelas J, Wang XH, Keenan TF, Peng SS, Berry JA, Wang K (2019) Air temperature optima of vegetation productivity across global biomes. Nat Ecol Evol 3: 772-779. https://doi.org/10.1038/s41559-019-0838-X.

Huang YQ, Zhao P, Zhang ZF, Li XK, He CX, Zhang RQ (2000) Transpiration of Cyclobalanopsis glauca (syn. Quercus glauca) stand measured by sap-flow method in a karst rocky terrain during dry season. Ecol Res 24: 791-801. https://doi.org/10.1007/s11284-008-0553-6.

Huete A, Didan K, Miura T, Rodriguez EP, Gao X, Ferreira LG (2002) Overview of the radiometric and biophysical performance of the MODIS vegetation indices. Remote Sens Environ 83: 195-213. https://doi.org/10.1016/S0034-4257(02)00096-2.

Jafary P, Sarab AA, Tehrani NA (2018) Ecosystem Health Assessment Using a Fuzzy Spatial Decision Support System in Taleghan Watershed Before and After Dam Construction. Environ Process 5: 807-831. https://doi.org/10.1007/s40710-018-0341-4.

Jakubauskas ME, Legates DR, Kastens JH (2002) Crop identification using harmonic analysis of time-series AVHRR NDVI data. Comput Electron Agric 37: 127-139. https://doi.org/10.1016/S01681699(02)00116-3. 
Jia GJ, Epstein HE, Walker DA (2004) Controls over intra-seasonal dynamics of AVHRR NDVI for the Arctic tundra in northern Alaska. Int J Remote Sens 25: 1547-1564. https://doi.org/10.1080/0143116021000023925.

Jiang L, Jiapaer G, Bao A, Guo H, Ndayisaba F (2017) Vegetation dynamics and responses to climate change and human activities in Central Asia. Sci Total Environ 599-600: 967-980.

Jiang ZC, Lian YQ, Qin XQ (2014) Rocky desertification in Southwest China: Impacts, causes, and restoration. Earth-Sci Rev 132: 1-12. https://doi.org/10.1016/j.earscirev.2014.01.005.

Kelly M, Tuxen KA, Stralberg D (2011) Mapping changes to vegetation pattern in a restoring wetland: Finding pattern metrics that are consistent across spatial scale and time. Ecol Indic 11: 263-273.

Kendall M (1975) Rank correlation methods. London: Charles Griffin.

582 Lai P, Zhang M, Ge Z, Hao B, Han X (2020) Responses of Seasonal Indicators to Extreme Droughts in Southwest China. Remote Sensing 12: 818. https://doi.org/10.3390/rs12050818.

Lanzante JR (1996) Resistant, Robust and Nonparametric Techniques for the Analysis of Climate Data: Theory and Examples, Including Applications to Historical Radiosonde Station Data. Int J Climatol 16: 11971226. https://dx.doi.org/10.1002/(SICI)1097-0088(199611)16:11<1197::AID-JOC89>3.0.CO;2-L.

Lamchin M, Wang SW, Lim CH, Ochir A, Pavel U, Gebru BM, Choi Y, Jeon SW, Lee WK (2020), Understanding global spatio-temporal trends and the relationship between vegetation greenness and

LeBauer DS, Treseder KK (2008) Nitrogen limitation of net primary productivityin terrestrial ecosystems is globally distributed. Ecology 89: 371-379. https://doi.org/10.1890/06-2057.1.

Leblon B, Alexander B, Chen J, White S (2001) Monitoring fire danger of northern boreal forests with NOAAAVHRR NDVI images. Int J Remote Sens 22: 2839-2846. https://doi.org/10.1080/01431160121183.

Li QP, Ma MG, Wu XD, Hong Y (2018) Snow cover and vegetation-induced decrease in global albedo from 2002 to 2016. J Geophys Res Atmos: 124-138. https://doi.org/10.1002/2017JD027010.

Li X, Li Y, Chen A, Gao M, Slette I, Piao SL (2019) The impact of the 2009/2010 drought on vegetation growth 
600 Li Z, Chen YN, Li WH, Deng HJ, G F (2015) Potential impacts of climate change on vegetation dynamics in

601 Central Asia. J Geophys Res Atmos 120: 12345-12356. https://doi.org/10.1002/2015JD023618.

602 Liu C, Yun Z, Chao S, Hou H, Li X (2012) Effect of Farm Manure on Dissolution of Underlying Carbonate Rocks and Atmospheric $\mathrm{CO}_{2}$ Source/Sink. https://doi.org/10.1007/978-3-642-27682-8_15.

604 Liu Y, Li Y, S.C L, Motesharrei S (2015) Spatial and Temporal Patterns of Global NDVI Trends: Correlations with Climate and Human Factors. Remote Sens 7: 13233-13250. https://doi.org/10.3390/rs71013233.

Liu ZJ, Liu YS, Li YR (2018) Anthropogenic contributions dominate trends of vegetation cover change over the farming-pastoral ecotone of northern China. Ecol Indic 95: 370-318. https://doi.org/10.1016/j.ecolind.2018.07.063.

Long XJ, Guan HD, Sinclair R, Batelaan O et al. (2018) Response of vegetation cover to climate variability in protected and grazed arid rangelands of South Australia. J Arid Environ 161: 64-71. https://doi.org/10.1016/j.jaridenv.2018.10.001.

612 Ma Mg, Veroustraete F (2006) Reconstructing pathfinder AVHRR land NDVI time-series data for the Northwest of China. Advances in Space Research 37: 835-840. https://doi.10.1016/j.asr.2005.08.037.

Ma Mg, Frank V (2006) Interannual variability of vegetation cover in the Chinese Heihe River Basin and its

Mann HB (1945) Nonparametric Tests Against Trend. Econ Soc 13: 245-259.

618 Martínez B, Gilabert MA (2009) Vegetation dynamics from NDVI time series analysis using the wavelet transform. Remote Sens Environ 113: 1823-1842. https://doi.org/10.1016/j.rse.2009.04.016.

620 Menzel A, Sparks TH, Estrella N, Koch E, Aasa A, Ahas R (2006) European phenological response to climate change matches the warming pattern. Glo Change Bio 12: 1969-1976.https:/doi.org/10.1111/j.1365-

623 Mueller T, Dressler G, Tucker CJ, Pinzon JE, Leimgruber P, Dubayah RO, Hurtt GC, Böhning-Gaese K, Fagan WF (2014) Human Land-Use Practices Lead to Global Long-Term Increases in Photosynthetic Capacity. Remote Sensing 6: 5717-5731. https://doi.org/10.3390/rs6065717.

626 Naudts K, Chen YY, McGrath MJ, Ryder J, Valade A, Otto J (2016) Europe's forest management did not mitigate climate warming. Science 315: 597-600. https://doi.org/10.1126/science.aad7270. 
628 Ndayisaba F, Hao G, Bao A, Hui G, Karamage F, Kayiranga A (2016) Understanding the Spatial Temporal Vegetation Dynamics in Rwanda. Remote Sens 8: 129-146. https://doi.org/10.1002/joc.823.

630 Neigh CSR, Tucker CJ, Townshend JRG (2008) North American vegetation dynamics observed with multiresolution satellite data. Remote Sens Environ 11

12: $\quad$ 1749-1772. https://doi.org/10.1016/j.rse.2007.08.018.

633 Nemani RR, Keeling CD, Hirofumi H, Jolly WM, Piper SC, Tucker CJ, Myneni RB, Running SW (2003) Climate-driven increases in global terrestrial net primary production from 1982 to 1999. Science 300: 1560-1563. https://dx.doi.org/10.1126/science.1082750.

Pelkey NW, Stoner CJ, Caro TM (2003) Assessing habitat protection regimes in Tanzania using AVHRR NDVI composites: Comparisons at different spatial and temporal scales. Int J Remote Sens 24: 2533-2558. https://doi.org/10.1080/01431160210155929.

Peng J, Ma J, Liu Q, Liu Y, Hu Y, Li Y, Yue Y (2018) Spatial-temporal change of land surface temperature across 285 cities in China: An urban-rural contrast perspective. Sci Total Environ 635: 487-497.

Peters GP, Andrew RM, Boden T, Canadell JG, Ciais P, Quéré CL, Marland G, Raupach MR, Wilson C (2012) The challenge to keep global warming below $2{ }^{\circ} \mathrm{C}$. Nat Clim Chang 3: 4-6.

Pettorelli N, Vik JO, Mysterud A, Gaillard JM, Tucker CJ, Stenseth NC (2005) Using the satellite-derived NDVI to assess ecological responses to environmental change. Trends Ecol 20: 503-510. https://doi.org/10.1016/j.tree.2005.05.011.Piao SL, Nan H, Huntingford C, Ciais P, Friedlingstein P,

Piao SL, Yin GD, Tan JG, Cheng L, Huang MT, Li Y (2015) Detection and attribution of vegetation greening trend in China over the last 30 years. Glob Change Biol 21: 1601-1609. https://doi.org/10.1111/gcb.12795. 

human footprint and implications for biodiversity conservation. Nat Commun 7: 1-11. https://doi.org/10.1038/ncomms12558.

Pouliot D, Latifovic R, Olthof I (2009) Trends in vegetation NDVI from 1km AVHRR data over Canada for the period 1985-2006. Int J Remote Sens 30: 149-168. https://doi.org/10.1080/01431160802302090.

Qin YW, Xiao XM, Dong JW, Zhou YT, Wang J, Doughty RB., Chen Y, Zou ZH, Moore B (2017), Annual dynamics of forest areas in South America during 2007-2010 at 50-m spatial resolution: Remote Sens Environ 201: 73-87.

Rousta I, Olafsson H, Zhang H, Moniruzzaman M, Krzyszczak J, Baranowski P (2020) Anthropogenic Factors Affecting the Vegetation Dynamics in the Arid Middle East. Preprints: 2020100208 https://doi.org/10.20944/preprints202010.0208.v2.

Seddon AWR, Maciasfauria M, Long PR, Benz D, Willis KJ (2016) Sensitivity of global terrestrial ecosystems to climate variability. Nature 531: 229-232. https://doi.org/10.1038/nature16986.

Song ZJ, Li RH, Qiu RH, Liu SY, Tan C, Li QP (2018) Global Land Surface Temperature Influenced by Vegetation Cover and PM2.5 from 2001 to 2016. Remote Sens 10: 2034-2052. https://doi.org/10.3390/rs10122034.

Spinoni J, Naumann G, Vogt JV (2017) Pan-European seasonal trends and recent changes of drought frequency and severity. Global Planet Change 148: 113-130. https://doi.org/10.1016/j.gloplacha.2016.11.013.

Stocker BD, Zscheischler J, Keenan TF, Prentice IC (2019) Drought impacts on terrestrial primary production underestimated by satellitemonitoring. Nat Geosci 12. https://doi.org/10.1038/s41561-019-0318-6.

Stow D, Daeschner S, Hope A, Douglas D, Petersen A, Myneni R, Zhou L, Oechel W (2003) Variability of the seasonally integrated normalized difference vegetationindex across the north slope of Alaska in the 1990s. Int J Remote Sens 24: 1111-1117. https://doi.org/10.1080/0143116021000021170.

Sun YL, Yang Y, Zhang L, Wang ZL (2015) The relative roles of climate variations and human activities in vegetation change in North China. Phys Chem Earth 87-88: 67-78. https://doi.org/10.1016/j.pce.2015.09.017.

Sun ZD, Chang NB, Opp C, Hennig T (2010) Evaluation of ecological restoration through vegetation patterns in the lower TarimRiver, China with MODIS NDVI data. Ecol Inform 6: 156-163. https://doi.org/10.1016/j.ecoinf.2010.10.002. 
Tong XW, Wang KL, Brandt M, Yue YM, Liao C, Fensholt R (2016) Assessing Future Vegetation Trends and Restoration Prospects in the Karst Regions of Southwest China. Remote Sens 8: 357. https://doi.org/10.3390/rs8050357.

Tong XW, Brandt M, Yue YM, Horion S, Wang Kl, Keersmaecker WD, Tian F, Schurgers G, Xiao Xm, Luo Yq (2018) Increased vegetation growth and carbon stock in China karst via ecological engineering. Nat Sustainability 1: 44-50. https://doi.org/10.1038/s41893-017-0004-X.

Tong XW, Wang KL, Yue YM, Brandt M, Liu B, Zhang CH, Liao CJ, Fensholt R (2017) Quantifying the effectiveness of ecological restoration projects on long-term vegetationdynamics in the karst regions of Southwest China. Earth ObsGeoinf 54: 105-113. https://doi.org/10.1016/j.jag.2016.09.013.

Trenberth KE, Dai A, Schrier GVD, Jones PD, Barichivich J, Briffa KR, Sheffield J (2014) Global warming and changes in drought. Nat Clim Change 4: 17-22. https://doi.org/10.1038/nclimate2067.

Vermote EF, Saleous EL, Nazmi Z, Christopher O (2002) Atmospheric correction of MODIS data in the visible to middle infrared: first results. Remote Sens Environ 83: 97-111. https://doi.org/10.1016/S00344257(02)00089-5.

Villa P, Boschetti M, Scozzari A, Vignudelli S (2014) Analysis of vegetation dynamics in middle east area during 2002-2013 in relation to the 2007-2009 drought episode. IEEE GeosciRemote Sens Symp.

Wang ZX, Liu C, Huete A (2003) From AVHRR-NDVI to MODIS-EVI: Advances in vegetation index research. Acta Ecol Sini 23: 979-987. https://doi.org/10.1023/A:1022289509702.

Wang KL, Yue YM, Brandt M, Tong XW (2019) Karst ecosystem observation and assessment at local and regional scales. Inter Carto Inter GIS 25:43-47. http://doi.org/10.35595/2414-9179-2019-2-25-43-47.

Wen ZF, Wu SJ, Chen JL, Lü MQ (2017) NDVI indicated long-term interannual changes in vegetation activities and their responses to climatic and anthropogenic factors in the Three Gorges Reservoir Region. Sci Total Environ 574: 947-959. http://doi.org/10.1016/j.scitotenv.2016.09.049.

Williams AP, Seager R, Abatzoglou JT, Cook BI, Smerdon JE, Cook ER (2015) Contribution of anthropogenic warming to California drought during 2012-2014. Geophys Res Lett 42: 6819-6828. https://doi.org/10.1002/2015GL064924.

Xie YC, Sha Zy, Yu M (2008) Remote sensing imagery in vegetation mapping: a review. J Plant Ecol 1: 19-23. https://doi.org/10.1093/jpe/rtm005. 
Xu L, Myneni RB, Chapin FS, Callaghan TV, Pinzon JE (2013) Temperature and vegetation seasonality diminishment over northern lands. Nat Clim Chang 3: 581-586. https://doi.org/10.1038/nclimate1836.

Yassoglou N (2000) History of desertification in the European Mediterranean. Pp. 9-15. In: Enne, G., D'Angelo, M., Zanolla, C. (Eds.), Indicators for Assessing Desertification in the Mediterranean. Proceedings of the International Seminar held in Porto Torres, Italy, 18-20 September, 1998. University of Sassari Nucleo Ricerca Desertificazion, Sassari, Italy.

Yang J, Pan SF, Dangal S, Zhang B, Wang SY, Tian HQ (2017), Continental-scale quantification of post-fire vegetation greenness recovery in temperate and boreal North America, Remote Sens Environ: 199:277-290. https://doi.org/10.1016/j.rse.2017.07.022.

Yu B, Zhang XB (2015) A physical analysis of the severe 2013/2014 cold winter in North America. J Geophys Res Atmos 120: 10149-10165. https://doi.org/10.1002/2015jd023116.

Yuan DX (1993) Environmental change and human impact on karst in south China, in Williams, P., ed., Karst terrains: environmental change and human impact. Catena Supplement 25.

Yuan DX (2000) Aspects on the new round land and resources survey in karst rock desertification areas of south China. Carsologica Sinica 2: 2-7.

Yuan, XL, Wang, WF, Cui, JJ, Meng, F, Kurban, A, \& De Maeyer, P (2017). Vegetation changes and land surface feedbacks drive shifts in local temperatures over Central Asia. Scientific Reports, 7(1). https://doi.org/10.1038/s41598-017-03432-2.

Yue YM, Zhang B, Wang KL, Zhang MY (2010) Spectral indices for estimating ecological indicators of karst rocky desertification. Int J Remote Sens 31: 2115-2122. https://doi.org/10.1080/01431160903382892.

Zaitchik BF, Evans JP, Geerken RA (2007) Climate and vegetation in the Middle East: Interannual variability and drought feedbacks. J Clim 20: 3924-3941. https://doi.org/10.1175/JCLI4223.1.

Zhang J (2008) Planning for comprehensive desertification control in Karst area of Guangxi Zhuang Autonomous Region. Prat Sci 25: 93-102.

Zhang L, Xiao J, Li J, Wang K, Lei L, Guo H (2012) The 2010 spring drought reduced primary productivity in southwestern China. Environ Res Lett 7: 045706. https://doi.org/10.1088/1748-9326/7/4/045706.

Zhang W, Jin F, Zhan J, Li Q, Ren H (2013) The possible influence of anonconventional El Niño on the severe autumn drought of 2009 in southwest China. J Clim 26: 8392-8405. https://doi.org/10.1175/JCLI-D12-00851.1.Zhao S, Cong D, He K, Yang H, Qin Z (2017) Spatial-Temporal Variation of Drought in 

Rep 7: 17473. https://doi.org/10.1038/s41598-017-17810-3.

744 Zhou Y, Li Z, Fensholt R, Wang K, Vitkovskaya I, Feng T (2015) Climate Contributions to Vegetation 745 Variations in Central Asian Drylands: Pre- and Post-USSR Collapse. Remote Sens 7: 2449-2470. https://doi.org/10.3390/rs70302449.

747 Zhu ZC, Piao SL, Myneni RB, Huang MT, Ning Z (2016) Greening of the Earth and its drivers. Nat Clim Chang 6: 791-795. https://doi.org/10.1038/nclimate3004. 